\title{
Altruism towards the end of life
}

\author{
Jean Davies Voluntary Euthanasia Society
}

\section{Author's abstract}

In the author's experience most normal healthy adults would like to have the choice of medical help to die if they become incurably ill and find their suffering intolerable. The reasons for this are explored, based on ten years of listening and talking about the subject to a wide variety of people in many countries.

The most familiar and common are the avoidance of futile suffering and the desire to retain autonomy. This paper concentrates on the dislike of losing independence and its closely associated wish to continue to behave altruistically. Some reasons for the general lack of recognition of the last two are suggested.

Patient autonomy is now recognised in the western democracies, at least in theory, as an essential component in medical decision-making about the incurably ill. It comes first, for example, in the theoretical framework within which the Wisconsin group has worked in drawing up their International Guidelines for Decisions to Forgo Curative Therapy (1). The President's Commission stresses the overriding nature of the individual's interest in fulfilling his/her own life plans (2). For the individual who looks ahead to the possible circumstances surrounding her own death this priority appears justified. The dread of losing the power to decide for oneself whether, for example, the balance between the onerous nature of the treatment offered outweighs the possible improvement in quality of life is indeed a most potent one. It is probably the major reason for completing an advance directive in the hope that one's wishes, expressed before becoming incompetent, will still prevail. Witnessing the impotence of a dying friend or relative to get the medical help to die that they are asking for is the commonest cause of trying to avoid being in such a position oneself (3).

It is commonly assumed that those who want the choice of voluntary euthanasia are motivated chiefly by their fear of an agonising death. Advances in

\section{Key words}

Altruism; voluntary euthanasia; patient autonomy; just distribution of resources. palliative care are cited in an attempt to assuage this anxiety (though the recent terminal sufferings of Mrs Boyes were not reassuring to doubters) (4). But even if the best hospice-type care were universally available to those approaching the end of life, it still would not satisfy another large group of those who want this choice to be one of their options. These are people who dread losing their independence. Any attempt to express the importance they attach to remaining self-sufficient domestically is kindly but firmly stifled as, for example, the protests against having a home-help, by a working-class woman. Her GP's reply was: 'You've looked after other people all your life and now it's our turn to look after you'. This produced acceptance of the offered help but a loss of self-esteem.

The affront that is caused to the habitually independent by the prospect of dependency is difficult to convey to those who have always relied on others for the mechanics of everyday living, for example, the congenitally physically handicapped. One of those most prolific in speaking and writing against any move towards decriminalising voluntary euthanasia is a young woman who has spent her life in a wheelchair. Naturally, and properly, she takes it for granted that others should do for her all the things she cannot do for herself. The feelings of a formerly independent person in a similar position are very different, and many of them fail to adapt to their new circumstances. When formerly active young men decide to die rather than live on as quadraplegics the reaction of many people is hostile. 'Look at X and Y' they say. 'In those circumstances $\mathrm{X}$ has written a book; $\mathrm{Y}$ has continued his work at the forefront of research in theoretical physics.' The implication is that we should all react in the same way to similar circumstances and the plain fact is that we do not. This attitude also implies that we are entitled to compare these contrasting behaviours and judge one more worthy than the other. It ignores the fact that only those suffering the adversity can judge the quality of the life remaining to them.

Infants must accept being fed, cleaned and placed where their carers choose to put them, but the normal toddler eagerly takes over at the earliest opportunity. The degree of being waited upon that 
used to be involved in the very widespread employment of domestic servants is now a relatively rare experience. Labour-saving machines and materials have made house-keeping an easily learnt and comparatively swiftly exercised skill; prepared foods have made the constant provision of home-cooked meals optional. So most school-leavers are used to looking after themselves physically, either habitually or on occasion. Of course there are still households, perhaps the majority, where the boys of the family are not routinely expected to exercise domestic skills to the same extent as their sisters. And those who have spent a large part of their formative years in an institution, such as a boarding school, are less likely to be accustomed to domestic self-service.

Perhaps it is not surprising then that the importance attached by most people to retaining the capability for independent daily living should be under-estimated by the decision-makers. Most of our senior politicians, civil servants, and lawyers are men (see Table 1), many of them middle-aged (or more) and an unrepresentative proportion of them, ex-public schoolboys. On all three counts they are less likely to be perturbed by the thought of accepting other people's help in the mechanics of everyday living than the average woman. And women predominate in the age group for which these considerations become pressing.

So far we have examined the self-regarding elements in the wish to be able to choose voluntary euthanasia towards the end of life. But many of those whose capabilities are dwindling are concerned about the effect that coping with their disabilities will have on those closest to them; some worry about the cost to society. This is the altruistic impulse, admired throughout history when expressed as selfsacrifice, from the mother to whom Solomon awarded the disputed baby, to Captain Oates walking out into the blizzard. Why should any suggestion by the failing person that they are becoming a burden be, as it commonly is, so vehemently denied? They are in fact a burden, and if they express it they are aware of the fact, so what good does it do to contradict them? Family and carers will naturally offer their most persuasive arguments, that it is a burden they are glad to accept, that it makes them feel more comfortable to be able to repay some of the care they have themselves received in the past.

\section{Table 1}

\begin{tabular}{lrr} 
& Men & Women \\
House of Lords & 1140 & 77 \\
Cabinet & 20 & 2 \\
House of Commons & 591 & 60 \\
Court of Appeal judges & 26 & 1 \\
High Court judges & 79 & 4 \\
Civil Servants (top grade) & 36 & 0 \\
\hline
\end{tabular}

They will say that it is one of the hallmarks of a civilised society to take proper care of those now unable to care for themselves. Few of the failing elderly retain the strength to go on arguing against the people on whom they depend, people who often wrongly describe the pressure they exert as 'counselling'. One old lady who did, maintained her position until her geriatrician ran out of arguments and herself joined the ranks of those advocating the decriminalisation of voluntary euthanasia (5)! But this is rare; usually the incurably ill accept that they have no alternative except compliance and they are silenced. This does not mean, of course, that their wishes change.

The altruism that they want to express, and if possible be free to act upon, is an almost universally felt human characteristic, despite the fact that two predominant features of contemporary life strongly suggest otherwise. The triumph of the economic theory of the market-place, that all will turn out for the best if everyone strives freely for his own best interest, supports the view that man is fundamentally an egocentric animal. The most pervasive and persuasive of the media, television, concentrates most on man the criminal, the aggressor, the terrorist, or, at the very least, man the cynic, the scoffer, to the extent that 'do-gooder' is now a term of abuse.

And yet, people still rush into their neighbours' burning houses to try to save lives. Even in the New York subway - admittedly in $1969-83$ per cent of those in the coach offered help to the researcher who collapsed in pretended pain (6). Hundreds of thousands of people regularly do voluntary work, sometimes of the most daunting nature, for no extrinsic reward. Blood continues to be donated. Amnesty letters flow in thousands to, and on behalf of, prisoners of conscience. Millions of pounds are given in the hope that they can be used to help other people, usually total strangers and often in remote countries, with very little prospect of knowing whether the donated money will actually achieve its aim. Research confirms what most of us have observed in ordinary life, that it is only psychopaths who show no concern for the effect of their behaviour on other people, and that individuals vary greatly in their tendency to behave altruistically (6).

That being so, why should we be so wary, not to say antagonistic, when those in their declining years express their regret about the costs they are unwillingly inflicting on the rest of us? Probably the answer is to be found in the fear that such a change in our attitude to the incurably ill would lead to the dying finding themselves under pressure to choose to die for the sake of benefiting others even though, for themselves, they would rather go on living. Must we assume that the careful practice of voluntary euthanasia could not guard against such pressure? Would not the doctor considering active euthanasia reflect on whether the patient's wish to die was abnormally self-sacrificing? Is the possibility of a 
patient choosing to die rather than drain the family by further futile treatment worse than the actual evil of the incurably ill being required to go on to the bitter end, no matter what they would choose, given the opportunity? The answers to these questions are not obvious and need thorough discussion.

In the only systematic practice of the legally tolerated choice of voluntary euthanasia for those approaching the end of life (7) the first duty of a doctor to whom a patient consistently expresses a wish for an earlier death, rather than a continuance of his reduced quality of life, is to listen. If she is unwilling to do more than that she must say so. The patient then has the opportunity to look for a doctor who may respond to his request; if found, that doctor's first duty is to talk, starting with the patient and then, with the patient's permission, involving caring relatives and possibly a counsellor or priest in the discussions. The doctor always listens particularly carefully to the nurses because they spend more time with the patient, and most patients speak more openly and informally to them than to their doctor. If the doctor suspects a treatable depression is the cause of the patient's attitude a psychiatrist's opinion is sought. Under these circumstances - and no one proposes that medical help to die should be given under any other - the chances of the fact escaping notice that the patient is trying to be too selfsacrificing rather than normally self-interested seem extremely small.

Unselfish behaviour used to be explicitly taught in the family and during religious observance; for some it still is, of course. But compared with previous generations we now make much less provision for this aspect of education, indeed as was said above, the role model provided by television includes a great deal of anti-social behaviour. Nevertheless we are not positively encouraged to be totally selfish except in regard to health care. From the inception of the NHS until quite recently doctors have been expected to recommend, and patients to accept, treatment as though health resources were infinite. Whatever else the recent changes in the NHS have achieved, they have at least brought out into the open the fact that health resources are limited and should be fairly distributed.

When deciding how much of these scarce resources should be devoted to caring for those nearing the end of life, the preferences of those people must be taken into account. It is too readily assumed that everyone is eager to postpone their own death as long as possible and at whatever cost. This is by no means the case. One woman said that she couldn't bear the thought of occupying a hospital bed with no prospect of recovery when that bed might be used by someone who was going to regain their health. Another, that knowing others would benefit from the medical resources she was foregoing in opting out of the last bit of unacceptably diminished life, would immeasurably add to her pleasure in the act, even though she made the decision primarily for her own sake. She compared it to giving a formerly beloved, but now unwanted, garment to the OXFAM shop instead of putting it into the dustbin. Hardwig describes his version of the same decision as 'donating your health care benefits' (8).

In framing social policy about the care of the dying we must recognise that we are not wholly selfish nor wholly self-sacrificing, we are complicated. Everyone will have his/her unique blend of ideas and preferences, even though many of them are widely shared. It is common for those who live to great age to have to adjust to the gradual loss of various faculties. Surely those nearing the end of life are not to be stripped of their human right to go on being altruistic as well? Caring for such patients involves listening to them with attention and respect, even if their medical advisers do not share their views. The idea that there is something praiseworthy about enduring unrelievable suffering until a 'natural' death occurs should not be thrust upon someone who sees no point in such a course of action. The rights to personal autonomy and to the practice of altruism are undisputed during competent adult life. Very strong arguments would be needed to justify the withdrawal of those rights from the dying.

This paper is based on ten years' work of listening, talking, reading and writing about voluntary euthanasia, while acting as Chairman, Secretary or Committee member of the Voluntary Euthanasia Society (England and Wales) and as President, Newsletter Editor or Board member of the World Federation of Right to Die Societies.

\section{References}

(1) Stanley J. Developing guidelines for decisions to forgo life-prolonging medical treatment. Fournal of medical ethics 1992 (supplement) 18: 4.

(2) President's Commission for the Study of Ethical Problems in Medicine and Biomedical and Behavioral Research. Washington, DC: Government Printing Office, 1983.

(3) Bogarde D. Pleading for the valley of the reaper. Sunday Telegraph 1991 Apr 22: books III: xiii.

(4) Chittenden M. Ordeal of the caring doctor who killed. Sunday Times 1992 Sept 20: 26.

(5) Bliss M. Voluntary euthanasia and the care of old people: the importance of the family. Conference paper. Voluntary euthanasia and the hospice movement: can we work together? 1988 May 21.

(6) Rushton J P. Altruism and society: a social learning perspective. Ethics 1982; 92: 425-446.

(7) NVVE. Guidelines for practice of voluntary euthanasia. (English edition available) Emmastraat 30, 1075 HV Amsterdam.

(8) Hardwig J. Donating your health care benefits. Hastings Center report 1988; 18: 8-9. 